\title{
Unconventional natural gas development and human health: thoughts from the United States
}

\section{"To date, few \\ epidemiological \\ $\mathrm{M}$}

or ecological

studies of the

effect of $U G D$

have been

conducted in

Australia. Without

these data, it is

difficult to assess

its health

impacts"

Madelon L Finke

Jake Hays

Adam Law

MD, FRCP 1,3

1 Weill Cornell Medical College, New York, NY, USA

2 PSE Healthy Energy,

New York, NY, USA

3 Cayuga Medical Center

Ithaca, NY, USA.

maf2011@med.

cornell.edu

doi: 10.5694/mjal5.00231 any countries are exploring the feasibility of unconventional gas development (UGD) as a component of their national energy policy. Broadly, UGD refers to natural gas produced from atypical reservoir types, including coal seam gas (CSG) and shale gas, which require extraction techniques different from those used for conventional production. The development of unconventional natural gas has been a game changer for the United States by significantly increasing domestic supply and lowering gas prices. However, there is a downside that must be considered, including potential harms to the environment, human and animal health and the world's climate.

Australia is not exempt from controversy over UGD. Since the mid 1990s, billions have been spent on CSG wells, liquefied natural gas plants and export facilities, primarily in Queensland, New South Wales and Victoria. Although CSG is a major industry in Australia, a focus on shale gas extraction, predominantly in Western Australia, South Australia and the Northern Territory, is underway to determine whether the geological properties are sufficient to support commercial production. Australia has large shale gas formations similar in size to the Marcellus and Barnett formations in the US.

The geology and extraction processes for CSG and shale gas differ in that coal seams are typically shallower than gas trapped in shale. Hydraulic fracturing is a wellstimulation method whereby highly pressurised fluid (consisting of water, sand and chemicals) is injected into a wellbore to open cracks in rock formations of low permeability. This technique is often used to release gas from coal seams and, when combined with directional drilling, to extract oil and gas from shale formations. Extracting gas from shale requires millions of litres of water per well; less water is required to extract CSG. However, the potential for harm to health and the environment is real and common to all forms of UGD.

Australia could learn much from the US experience. We acknowledge concerns from Australia ${ }^{1}$ and argue that if UGD (particularly from shale) continues to expand, the health and environmental impacts must be adequately addressed. Specifically, UGD policies should be informed by empirical evidence based on actual experience rather than theoretical solutions and the assurance of best practices. $^{2}$

\section{Hazards, risks and exposure pathways}

A significant part of the UGD controversy focuses on the hundreds of toxic chemicals used in the hydraulic fracturing process. Fracturing fluids contain organic and

\section{Summary}

- If unconventional gas development (UGD) continues to expand in Australia, the potential health and environmental impacts should be adequately addressed and preventive public health measures should be implemented.

- The United States has embraced UGD and has decades of experience that could be beneficial to Australia as stakeholders debate the potential benefits and harms of the technique.

- Additional research on the health impacts of UGD is necessary. Baseline and trend morbidity and mortality data need to be collected to assess changes in population health over time. To date, few health or epidemiological studies have been conducted, so it remains difficult to assess actual health outcomes.

- In the absence of scientific consensus, there are two possible risks: failing to develop unconventional natural gas when the harms are manageable; or developing it when the harms are substantial. Many government bodies around the world have chosen to minimise the risk of the latter until the impacts of UGD are better understood.

- Policies should be informed by empirical evidence based on actual experience rather than assurance of best practices. There is a strong rationale for precautionary measures based on the health and environmental risks identified in the scientific literature.

inorganic chemicals known to be health damaging. ${ }^{3}$ Hazardous compounds have been identified in wastewaters produced by the process, including salts, chlorides, heavy metals (eg, cadmium, lead and arsenic), volatile organics (eg, benzene, toluene, ethylbenzene and xylene) and, depending on the geochemistry of the target reservoir, naturally occurring radioactive materials (eg, radium 226 and radon). ${ }^{4,5}$ Recent evidence from Pennsylvania suggested a positive association and upward trend with indoor radon concentrations and shale gas development. ${ }^{6}$

Human exposure to toxic chemicals and other pollutants associated with UGD can occur throughout the life cycle of UGD. These include surface leaks, spills, releases from holding tanks, venting, well-casing failure and accidents during transportation of fluids. ${ }^{7}$ Air pollutants such as volatile organic compounds, aromatic hydrocarbons, diesel particulate matter and tropospheric ozone can come into contact with human populations from atmospheric dispersion of UGD air emissions. As with air, risks to water quality can occur over the full life cycle of UGD, 
and surface water and aquifer contamination has been linked to UGD on numerous occasions. ${ }^{8-12}$

Potential exposure to endocrine-disrupting chemicals (EDCs) is an increasing concern in the context of UGD, primarily because these chemicals, even at low levels of exposure, interfere with the body's endocrine system and multiple other physiological systems to produce adverse developmental, reproductive, neurological and immune effects. ${ }^{13}$ EDCs present a unique hazard particularly during fetal and early childhood growth and development, when organ and neural systems are forming. ${ }^{14}$ The epigenetic effects of EDCs must be better understood. Unfortunately, epigenetic research has been hampered in the US by an incomplete listing of chemicals used in hydraulic fracturing.

There are other health, environmental and social concerns associated with UGD, including its contribution to methane emissions and climate change; ${ }^{15,16}$ depletion of water supplies (of particular importance to Australia, as it is considered to be the world's driest inhabited continent); the management (storage, treatment, and disposal) of wastewater produced; noise pollution; ${ }^{17}$ social justice and community concerns; ${ }^{18}$ seismic activity; ${ }^{19}$ and ecosystem disruption and habitat loss. ${ }^{20}$ Of the more than 480 peer-reviewed journal articles pertaining to these impacts (as of May 2015), more than $75 \%$ were published since 1 January 2013; the overwhelming majority of these focus on UGD and the impact on the environment in the US. ${ }^{21}$ The rapid growth in UGD activities has occurred without health and epidemiological studies designed to assess the short- and long-term impacts of UGD.

\section{The need for empirical studies}

As the pace of UGD increases globally, well designed peer-reviewed studies on its health impacts are needed. Health impact assessments, environmental epidemiological studies and ecological studies to assess the burden of disease in populations, as well as descriptive trend studies, are important means to empirically document the impact of UGD on health and wellbeing. Baseline and trend morbidity and mortality data need to be collected and analysed before and during UGD activity in order to assess changes in population health over time. Unfortunately, in the US, few health impact assessment studies have been conducted before or even during UGD activities, and there have been even fewer well designed epidemiologic studies.

Although adverse health effects may appear fairly quickly after exposure in some individuals, specific diseases may take more time to develop (eg, cancers; harm to the reproductive, endocrine and nervous systems; and delayed developmental effects). A higher incidence of asthma, cancers, heart disease and the effects of endocrine disruption on the developing fetus as well as infants and children only become evident over time, and confounding factors must be taken into account. Certainly, the potential for harm will vary by proximity to operations; type, pathways, duration and route(s) of exposure; and the

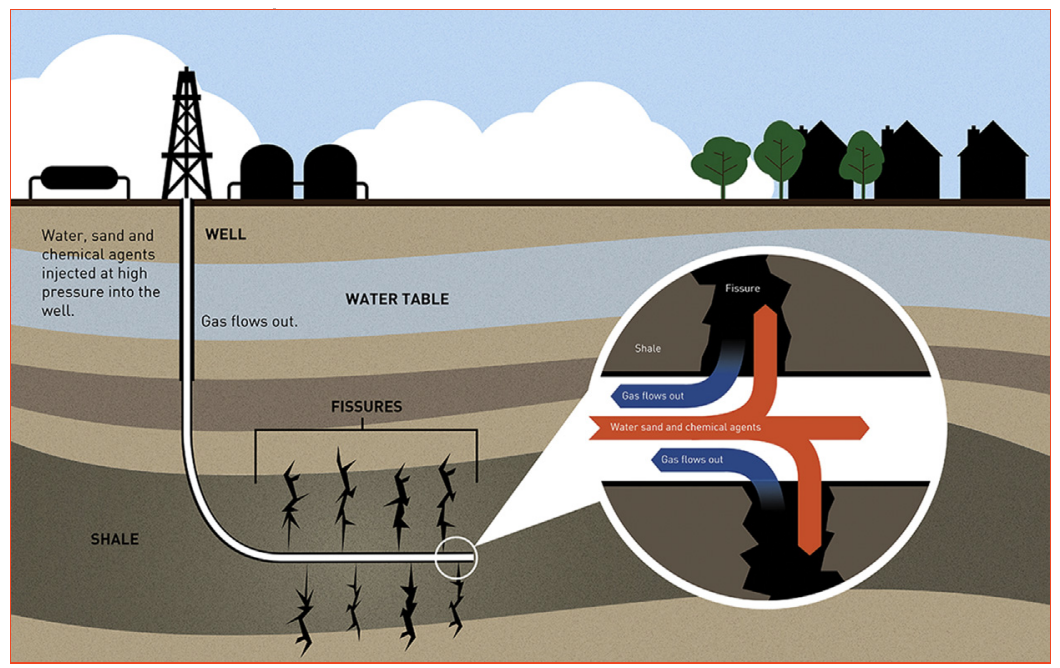

safety culture of the operators. Comparison populations are necessary to assess the association of the hypothesised risk factors to disease development.

The limited evidence from the US should serve as a warning to those intent on expanding gas extraction in the absence of epidemiological studies. For example, an association study analysing randomised survey data suggested higher reported health symptoms per person among residents living closer to natural gas wells. ${ }^{22}$ Another study demonstrated a greater prevalence of some adverse birth outcomes, including congenital heart defects for neonates born to mothers living in areas of higher-density UGD. ${ }^{23}$ Yet the current evidence leaves many questions unanswered. This neither implies nor excludes that there is little or no harm from UGD activities. There have been numerous reports of clinical signs and symptoms in the US, including its impacts on the respiratory system (sinus problems, coughing, throat soreness or irritation), the integumentary system (rashes or skin irritation), the neurological system (headaches, dizziness) and the gastrointestinal system (nausea or abdominal pain). ${ }^{24}$ A causal connection to UGD has not yet been established by analytic research, but reported symptoms have been consistent across geographical space and are compatible with human exposure to contaminants associated with UGD. Self-reported survey data and other qualitative research already exist. ${ }^{25}$ These can help generate hypotheses and serve as the basis for more rigorous, analytic epidemiological investigations, which are needed to assess short- and long-term impacts of UGD on health.

\section{Concluding thoughts and policy considerations}

Ultimately, in any nation, federal and local governments will have to assess the potential costs and benefits of UGD. As well as the various concerns outlined above, this consideration must also take into account production potential based on reserve estimates and capital expenditures required to develop unconventional natural gas. 
This is particularly important for Australia, which will need to invest heavily in transmission infrastructure and export facilities.

Regardless of what governmental bodies decide, preventive public health measures should be put in place before expanding the development of unconventional natural gas. To assess trends and changes in morbidity and mortality, baseline data should be collected in areas where UGD is planned. There should be a system to track the risk of exposure to environmental agents and the incidence and prevalence of diseases. This could take the form of a health registry or roster, health response line, community reporting systems, or an environmental public health tracking system similar to that developed by the US Centers for Disease Control and Prevention (http://www.cdc.gov/nceh/tracking).

As Australia considers expanding UGD, particularly the extraction of shale gas, it should not necessarily follow the lead of the US. In the US, regulatory actions have generally been weak or ineffective and little attention has been paid to monitoring adverse harms to humans and animals. There must be full transparency in measuring, regulating and monitoring the impacts of the process; studies must be done to measure the potential short- and long-term harm to the environment as well as to animal and human health. To date, few epidemiological or ecological studies of the effect of UGD have been conducted in Australia. Without these data, it is difficult to assess its health impacts.

Many countries have decided to exercise caution as they debate the pros and cons of UGD. New York State recently banned high-volume hydraulic fracturing (and, effectively, shale gas development) based on a recommendation by the state Department of Health after a comprehensive review of the scientific literature. ${ }^{26}$ France and Bulgaria have banned the practice, and Scotland and Wales recently imposed moratoria. In Germany, the government has upheld a de-facto moratorium on shale gas development amid environmental and public health concerns, but is currently considering a nationwide law that would effectively delay shale gas development for at least 5 years.
As in US, UGD bans in Canada have been mixed. Large-scale UGD has been ongoing in parts of Western Canada (Alberta), whereas more densely populated parts of the country (Nova Scotia, Newfoundland, Quebec, New Brunswick) have imposed indefinite bans or moratoria on high-volume hydraulic fracturing. Other countries, however, are intent on moving forward despite the lack of more evidence of environmental and public health safety. China joined the US and Canada as only the third country in the world to produce shale gas on a commercial scale. Because of its dependency on Russian natural gas, Poland was especially keen on development and initial estimates from the Polish Geological Institute predicted enough shale gas resources to supply the country for 35-65 years. ${ }^{27}$ However, foreign investors have since pulled out of the country because of regulatory delays, public opposition and test flow results not high enough for commercial production. Australia has been somewhat divided on the issue and although there is significant interest in the expansion of CSG operations and shale gas exploration, some jurisdictions have implemented moratoria, including Tasmania and Victoria.

There is a strong rationale for precautionary measures. ${ }^{28}$ In the absence of scientific consensus, policymakers face two possible risks: either failing to develop unconventional natural gas when the harms are manageable, or developing it when the harms are substantial. Given recent evidence from the US, we believe there is strong support for minimising the risk of the latter. Based on the US experience, there have been significant impacts to the environment and health under current lax "best practices" and equally lax regulations. Australia would do well to consider the emerging evidence from the US as it debates the feasibility of the expansion of UGD.

Acknowledgements: The content of this article is based on a keynote address given by Madelon Finkel at a seminar on CSG, fracking and health held at the University of Sydney on 24 November 2014

Competing interests: No relevant disclosures.

Provenance: Not commissioned; externally peer reviewed. 트

(c) 2015 AMPCo Pty Ltd. Produced with Elsevier B.V. All rights reserved.

References are available online at www.mja.com.au. 
1 Coram A, Moss J, Blashki G. Harms unknown: health uncertainties cast doubt on the role of unconventional gas in Australia's energy future. Med J Aust 2014; 200: 210-213. https://www.mja.com.au/journal/2014/200/4/harmsunknown-health-uncertainties-cast-doubt-roleunconventional-gas-australias

2 Law A, Hays J, Shonkoff SB, Finkel ML. Public Health England's draft report on shale gas extraction. BMJ 2014; 348: g2728-g2728.

3 Aminto A, Olson MS. Four-compartment partition model of hazardous components in hydraulic fracturing fluid additives. $J$ Nat Gas Sci Eng 2012; 7: 16-21.

4 Nelson AW, May D, Knight AW, et al. Matrix complications in the determination of radium levels in hydraulic fracturing flowback water from Marcellus Shale. Environ Sci Technol Lett 2014; 1: 204-208.

5 Maguire-Boyle SJ, Barron AR. Organic compounds in produced waters from shale gas wells. Environ Sci: Processes Impacts 2014; 16: 2237-2248.

6 Casey JA, Ogburn EL, Rasmussen SG, et al. Predictors of indoor radon concentrations in Pennsylvania, 1989-2013. Environ Health Perspect 2015. http://dx.doi.org/10.1289/ehp.1409014 (accessed Aug 2015).

7 Shonkoff SB, Hays J, Finkel ML. Environmental public health dimensions of shale and tight gas development. Environ Health Perspect 2014; 122: 787-795.

8 Jackson RB, Vengosh A, Darrah TH, et al. Increased stray gas abundance in a subset of drinking water wells near Marcellus shale gas extraction. Proc Natl Acad Sci U S A 2013; 110: $11250-11255$.

9 Llewellyn GT, Dorman F, Westland JL, et al. Evaluating a groundwater supply contamination incident attributed to Marcellus Shale gas development. Proc Natl Acad Sci U S A 2015; 112: 6325-6330.

10 Pennsylvania Department of Environmental Protection. Water Supply Determination Letters. 2014. http://files.dep.state.pa. us/OilGas/BOGM/BOGMPortalFiles/OilGasReports/ Determination_Letters/Regional_Determination_Letters.pdf (accessed Apr 2015).

1 Fontenot BE, Hunt LR, Hildenbrand ZL, et al. An evaluation of water quality in private drinking water wells near natural gas extraction sites in the Barnett Shale formation. Environ Sci Technol 2013; 47: 10032-10040.

12 Gross SA, Avens HJ, Banducci AM, et al. Analysis of BTEX groundwater concentrations from surface spills associated with hydraulic fracturing operations. J Air Waste Manag Assoc 2013; 63: 424-432.

13 Kassotis CD, Tillitt DE, Davis JW, et al. Estrogen and androgen receptor activities of hydraulic fracturing chemicals and surface and ground water in a drilling-dense region. Endocrinology 2014; 155: 897-907.

14 Diamanti-Kandarakis E, Bourguignon J-P, Giudice LC, et al. Endocrine-disrupting chemicals: an Endocrine Society scientific statement. Endocr Rev 2009; 30: 293-342.
15 Schneising 0, Burrows JP, Dickerson RR, et al. Remote sensing of fugitive methane emissions from oil and gas production in North American tight geologic formations. Earth's Future 2014; 2014EF000265.

16 McJeon $\mathrm{H}$, Edmonds J, Baver N, et al. Limited impact on decadal-scale climate change from increased use of natural gas. Nature 2014; 514: 482-485.

17 McCawley M. Air, noise, and light monitoring results for assessing environmental impacts of horizontal gas well drilling operations (ETD-10 Project). Charleston, WV: West Virginia Department of Environmental Protection, 2013. http://wvwri. org/wp-content/uploads/2013/10/A-N-L-Final-Report-FORWEB.pdf (accessed Apr 2015).

18 Ogneva-Himmelberger Y, Huang L. Spatial distribution of unconventional gas wells and human populations in the Marcellus Shale in the United States: vulnerability analysis. Appl Geogr 2015; 60: 165-174.

19 Keranen KM, Weingarten M, Abers GA, et al. Sharp increase in central Oklahoma seismicity since 2008 induced by massive wastewater injection. Science 2014; 345: 448-451.

20 Allred BW, Smith WK, Twidwell D, et al. Ecosystem services lost to oil and gas in North America. Science 2015; 348: 401-402.

21 Hays J, Shonkoff SBC. Toward an understanding of the environmental and public health impacts of shale gas development: an analysis of the peer reviewed scientific literature, 2009-2014. PSE Healthy Energy, 2015. http://www. psehealthyenergy.org/data/Database_Analysis_2015.1_27_1.pdf (accessed Apr 10).

22 Rabinowitz PM, Slizovskiy IB, Lamers V, et al. Proximity to natural gas wells and reported health status: results of a household survey in Washington County, Pennsylvania. Environ Health Perspect 2015; 123: 21-26.

23 McKenzie LM, Guo R, Witter RZ, et al. Birth outcomes and maternal residential proximity to natural gas development in Rural Colorado. Environ Health Perspect 2014; 122: 412-417.

24 Steinzor N, Subra W, Sumi L. Investigating links between shale gas development and health impacts through a community survey project in Pennsylvania. New Solut 2013; 23: 55-83.

25 Bamberger M, Oswald RE. Impacts of gas drilling on human and animal health. New Solut 2012; 22: 51-77.

26 New York State Department of Health. A public health review of high volume hydraulic fracturing for shale gas development. 2014. https://www.health.ny.gov/press/reports/docs/high_ volume_hydraulic_fracturing.pdf (accessed Apr 2015).

27 Polish Geological Institute - National Research Institute. Assessment of shale gas and shale oil resources of the Lower Paleozoic Baltic-Podlasie-Lubin Basin in Poland. First report. Warsaw, March 2012. http://www.pgi.gov.pl/en/mineralresources-en/shale-gas/4744-shale-gas-estimates.html (accessed Aug 2015)

28 de Melo-Martín I, Hays J, Finkel ML. The role of ethics in shale gas policies. Sci Total Environ 2014; 470-471: 1114-1119. 